\title{
Evaluating System of a Country's Development Potential and the Analysis of Climate's Impact
}

\author{
Ning Fang \\ Department of Economic Management, North China Electric Power University, Baoding, Hebei \\ 071003, PR China \\ 2728243070@qq.com
} Keywords: Fragile State Index, Evaluating system, Entropy Weight Method, GRNN, Climate
change.

\begin{abstract}
In this paper, fragility which is measured by Fragile State Index is used to represent a country's development potential. Then, we establish an evaluating system to measure a country's fragility based on GRNN model and Entropy weight method. Besides, we analyze the impact of climate change on the results. And taking Afghanistan as an example, we analyze the country's fragility. First, we establish the basic structure of evaluating system based on AHP. Then, the Entropy Weight Method is applied to solve the correlation between the principle layer and the indicator layer, while the GRNN model is used to investigate the relation between target layer and principle layer. In order to find the influence caused by the climate change in Afghanistan, we introduce a sub-indicator layer under the indicator layer, and the relationship between these two layers is solved based on Multiple Linear Regression. Finally, we get a comparison between the situation with climate change and without climate change. We find that in the situation that climate change is absent, Afghanistan's vulnerability is significantly better than the situation with climate change. Therefore, Afghanistan should step up its efforts to protect the environment in order to improve its vulnerability and achieve better development.
\end{abstract}

\section{Introduction}

At present, whether a country has good development potential has become an important symbol of the overall strength of a country, scientists often use fragility to measure the development potential of a country. Meanwhile, fragile state index becomes a quantitative indicator of a country's fragility. Therefore, the study of fragile states index has become a core issue discussed by the western academics and policy makers when referring to global security, development and poverty problems. [1,2] There are still many deficiencies in these evaluating systems, such as the strong subjectivity in the judging process and the lack of reliable mathematical support in many evaluation systems. Besides, according to the reference [7], climate change alone does not directly trigger a country's fragility, but evidence suggests that it enables to exacerbate a country's fragility indirectly when it influences other indicators. We will use a relatively rigorous evaluation system to assess a country's vulnerability, while analyzing the impact of climate change.

\section{Fragile State Index}

\subsection{The Model}

Fragile State index is used to measure the vulnerability of a country. The greater fragile state index is, the greater the vulnerability of this country is. [2] In other words, the situation of this country is more dangerous.

\subsubsection{The Structure of Evaluating System}

According to the reference [1], we use AHP to determine the structure of our evaluating system. We determine that our system will consist of three layers that the target layer, the principle layer, and the index layer. We also refer to this reference to select principles and indicators. The overall structure is shown in Fig.1. 


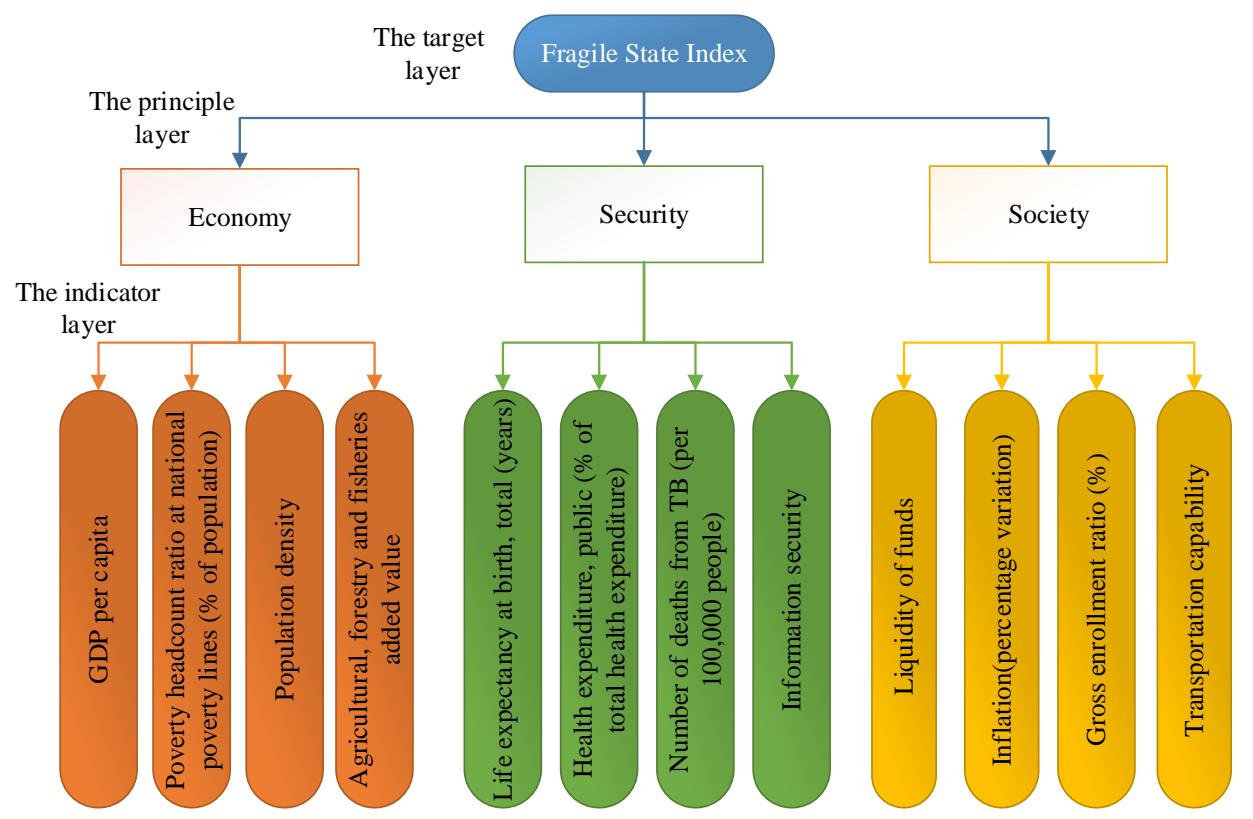

Fig. 1 The structure of the evaluating system

\subsubsection{The Solution of the Relationship Between Different Layers}

Firstly, we get the relationship between the principle layer and the indicator layer based on Entropy Weight Method [3], as is shown in Tab.1.

Tab. 1 The weights of indicators

\begin{tabular}{|c|c|c|}
\hline The principle layer & The indicator layer & Weights \\
\hline \multirow{4}{*}{ Economy $\left(P_{1}\right)$} & GDP per capita $\left(R_{1}\right)$ & 0.27 \\
\cline { 2 - 3 } & Poverty headcount ratio at national poverty lines $\left(R_{2}\right)$ & 0.12 \\
\cline { 2 - 3 } & Population density $\left(R_{3}\right)$ & 0.19 \\
\cline { 2 - 3 } & Agricultural, forestry and fisheries added value $\left(R_{4}\right)$ & 0.42 \\
\hline \multirow{5}{*}{ Security $\left(P_{2}\right)$} & Life expectancy at birth, total $\left(R_{5}\right)$ & 0.27 \\
\cline { 2 - 3 } & Health expenditure, public $\left(R_{6}\right)$ & 0.07 \\
\cline { 2 - 3 } & Number of deaths from TB $\left(R_{7}\right)$ & 0.24 \\
\cline { 2 - 3 } & Information security $\left(R_{8}\right)$ & 0.42 \\
\hline \multirow{3}{*}{ Society $\left(P_{3}\right)$} & Liquidity of funds $\left(R_{9}\right)$ & 0.33 \\
\cline { 2 - 3 } & Inflation $\left(R_{10}\right)$ & 0.32 \\
\cline { 2 - 3 } & Gross enrollment ratio $\left(R_{11}\right)$ & 0.14 \\
\cline { 2 - 3 } & Transportation capability $\left(R_{12}\right)$ & 0.21 \\
\hline
\end{tabular}

Then, we get the relationship between target layer and principle layer based on GRNN model [4].

The GRNN neural network consists of four layers, including the input layer, the model layer, the summation layer and the output layer. We select 15 training samples which come from the data of 15 countries and three independent variables which consist of economy, security and society. These samples and variables become the input of the network. And the level of Fragile State Index is the output of the network whose value ranges from 0.5 to 6 .

The deviation between actual value and training data also proves that our model has great reliability as shown in Fig.2.Therefore, the network is reliable. 


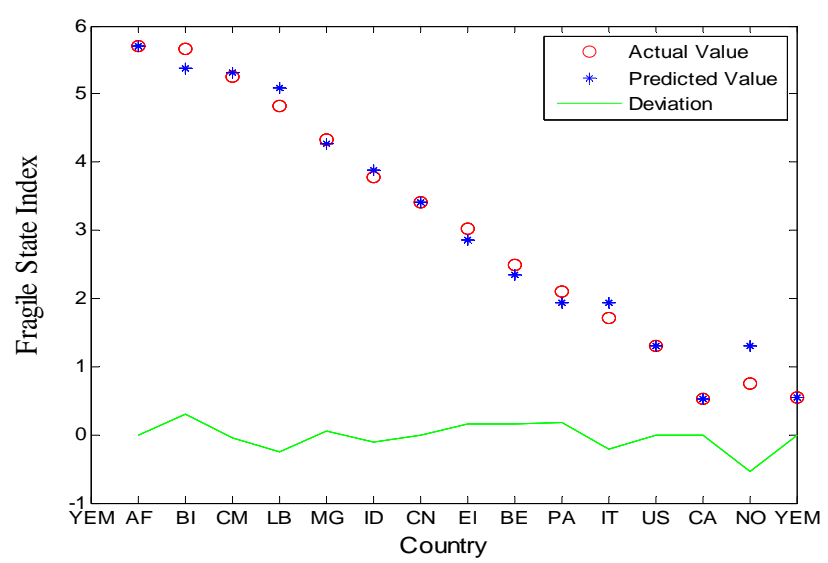

Fig.2 The deviation of the network’s training

\subsection{The Introduction of Sub-Indicator Layer}

According to the analysis of the impact of climate change on fragile state index in relevant references[6,7], we decide that the sub-index layer is composed of precipitation(S1), temperature(S2) and land carrying capacity(S3).These sub-indicators represent the impact of climate change.

First, we use Multiple Linear Regression [5] analysis to find the linear relationship between the 12 indicators in the indicator layer and the variables in the sub-index layer. According to the raw data, the regression equations and relational degree between 12 indicators and 3 sub-indicators can be obtained. And the values of relational degree can are shown in Tab.2.

Tab.2 The analysis of relational degree

\begin{tabular}{|c|c|c|c|}
\hline Indicator & Relational degree & Indicator & Relational degree \\
\hline$R_{1}$ & 0.657725067 & $R_{7}$ & 0.777099365 \\
\hline$R_{2}$ & 0.780491184 & $R_{8}$ & 0.513307789 \\
\hline$R_{3}$ & 0.770287374 & $R_{9}$ & 0.105171779 \\
\hline$R_{4}$ & 0.753472225 & $R_{10}$ & 0.061186498 \\
\hline$R_{5}$ & 0.785167847 & $R_{11}$ & 0.253592539 \\
\hline$R_{6}$ & 0.645863686 & $R_{12}$ & 0.661615006 \\
\hline
\end{tabular}

Then, we assume that there is a strong linear relationship between the dependent variable and the independent variable only if relational degree is greater than 0.7 , which include R2, R3, R4, R5 and R7.

\subsection{The Application of Model in Afghanistan}

First, considering the effects of climate change, we find the raw data [8, 9] of 12 indicators of Afghanistan from 1995 to 2015 . These data are substituted into basic model, and we can figure out the Fragile State Index of Afghanistan.

Then, we still find the raw data of 12 indicators of Afghanistan from 1995 to 2015. For these indicators including R2, R3, R4, R5 and R7, we replaced raw data with the best values during previous years [9] to remove the effects of climate change on Fragile State Index. Then, these data is substituted into the model, and we can figure out the Fragile State Index of Afghanistan again.

By comparing two sets of Fragile State Index as shown in Fig.3, we can obviously find the influence of due to climate change. 


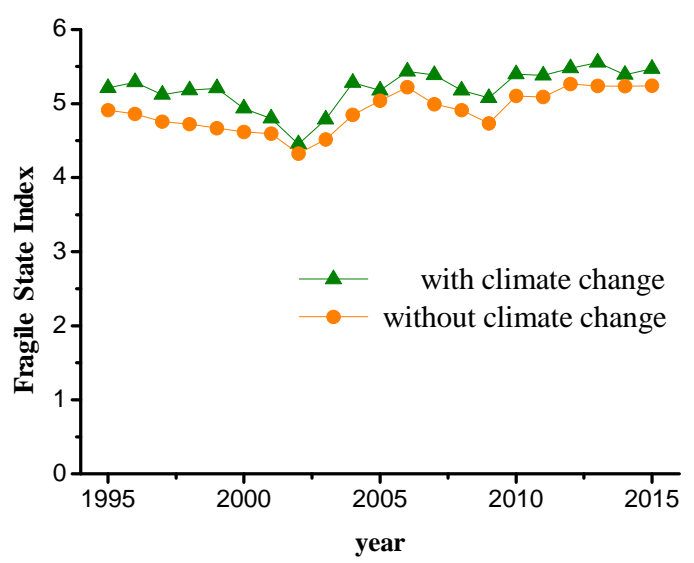

Fig.3 The influence by the effect of climate change.

\section{Conclusion}

As is shown in the Fig.3, the curve that with climate change can represent the Fragile State Index of Afghanistan from 1995 to 2005.In 2002, the index reached its lowest level in nearly a decade, indicating that the country in this year is relatively stable. For the remaining years, the fragile state index in Afghanistan has always been at a high state, that is, the country of Afghanistan has been fragile.

According to the comparison between the situation with climate change and without climate change, we can find that if we remove the effects of climate change, we can see that the annual vulnerability index in Afghanistan will decrease significantly, indicating that climate change will have a significant impact on the vulnerability of a country. Meanwhile, when fragile state index is low, such as in 2002, the impact of reducing climate change effectively will be significantly greater than those that are high. Therefore, the poorer and fragile a country, the more the country should consider how to reduce the impact of climate change on a country.

Afghanistan should step up its efforts to protect the environment in order to improve its vulnerability and achieve better development.

\section{References}

[1]. Information on http://fundforpeace.org/fsi/data

[2]. Tian-xu Liu, Tao Wu, "Evaluation Criteria of Fragile States," Theoretical Exploration, Apr, 2016

[3]. Yang Li, "Evaluation of Coal Mine Emergency Rescue Capability based on Entropy Weight Method,” Soft science research results and dynamic journals, Jul, 2013

[4]. Yun Tan, "GRNN model construction and MATLAB implementation," SCIENCE \& TECHNOLOGY INFORMATION, Sep, 2009

[5]. Dan Ren, "Design and implementation of the movie box office predicting system based on multivariate linear regression model,” Master's thesis of Sun yat-sen university, May, 2015

[6]. Xiao-nong Zhou, “Climate change affects human health and social security,” Chinese Weather Report, Sep, 2009

[7]. Qian Zhang and Hui-xin Meng, "Social Vulnerability and Poverty to Climate Change: A Summary on Foreign Research,” Theoretical China Agricultural University Journal of Social Sciences Edition, vol.31, no.2, pp.56-67, Jun, 2016.

[8]. Information on http://www.shihang.org/

[9]. Information on http://www.epsnet.com.cn/ 